DOI:10.5216/racs.v5.65693

\title{
Aprender para resignificar, resignificar para aprender: el caso del fomento de una educación bilingüe para las comunidades de San Juan Chamula, Chiapas, México
}

\author{
Martina Hernández Sánchez ${ }^{1}$
}

\section{RESUMEN}

Este trabajo revela los problemas, retos, desafíos y contradicciones de los maestros indígenas del municipio de Chamula, del Estado de Chiapas, México, durante sus prácticas en las aulas en el nivel de educación primaria. Asimismo, da cuenta de cómo un grupo de docentes organizados, desde el proyecto Milpas Educativas ${ }^{2}$, hacen un esfuerzo por llevar una educación distinta basada en el Método Inductivo Intercultural acuñado por Jorge Gasché, en el que plantea un proceso pedagógico significativo para la alfabetización en la lengua de la comunidad, articulando la pedagogía con una posición política, didáctica, jurídica y pertinente.

PALABRAS CLAVE: Educación indígena instituida. Prácticas alternativas y educación para el fomento del bilingüismo.

\section{TSOS-K’OP}

Li amtel lie chal sventa sk'oplal, k'uyepal k'opetik oy yu unik li a'k chan junetik tas lumal chamoetik, tas lumal Chiapas, México, ja' no ox tok li chanjunetik ta primaria. Oy la uni jun chop ta ak' chanjunetik ta las pasik jun a'mtelal ti lek la ta nopesel xchiuk la ja oy jun winik ti snaoj smelolal k'uselan ta nopel, schanuptasel ta ololetik taj lumaltik, ja suy "nopesel ta choptik", ti oyuk smelolal li k'uselan stak ak'el ta a chanop jun ololetike, jech stok taj am'tele ja la yich'oj tas venta Jorge Gasché, taj winike ja staoj ta to ku'lanel, yiloj ti lek ta am'telanel tas stojolal ti ololetik, yu un las tok'olanik tis melolal k'uslejal chanjun taj lumaltik. Cha al toj ep sk'oplal taj am'te le, oy smelolal ja' no'ox sk'an ta nopesel.

LEKIL SKOPLAL: Slekilal chanjun taj lumaltik. Slekilal amtel yu un chanjunetik xchiuk lek stusel chanjunetik sventa k'oplal batsik'op xchiuk kaxlan k'op.

1 Universidad Pedagógica Nacional (UPN), Ciudad de México, CDMX, México. E-mail: martinahernandez299@gmail.com

2 Es un proyecto colaborativo que tiene antecedentes profundos arraigados en las luchas que han librado organizaciones y movimientos indígenas del continente americano y de México por construir una educación social, cultural, epistémica y pedagógicamente pertinente y relevante, con un enfoque inductivo e intercultural, centrada en la articulación entre teoría y praxis. 


\section{RESUMO}

Este trabalho revela os problemas, desafios, desafios e contradições dos professores indígenas do município de Chamula, do Estado de Chiapas, México, durante suas práticas em sala de aula do ensino fundamental. Da mesma forma, dá conta de como um grupo de professores organizados, do projeto Milpas Educativas, se esforça por realizar uma formação diferenciada a partir do Método Indutivo Intercultural cunhado por Jorge Gasché, no qual propõe um significativo processo pedagógico para a alfabetização no linguagem da comunidade, articulando a pedagogia com um posicionamento político, didático, jurídico e pertinente.

PALAVRAS-CHAVE: Educação indígena instituída. Práticas alternativas e educação para a promoção do bilinguismo.

\section{Introducción}

San Juan Chamula es una población del estado mexicano de Chiapas. Es uno de los 17 municipios que forman la Región de los Altos. Se encuentra a diez kilómetros de San Cristóbal de las Casas y a doce kilómetros de San Andrés Larráinzar. San Juan y San Andrés son localidades habitadas por un gran número de tsotsiles. San Juan Chamula es también la cabecera del municipio de Chamula y está ubicado en las zonas más altas de Chiapas, se ubica en el Altiplano Central predominando el paisaje montañoso, en la localidad se han conservado las culturas, tradiciones y costumbres prehispánicas.

En el contexto del estado de Chiapas, México, donde prevalece el mayor déficit educativo, el analfabetismo, la marginación y la pobreza extrema, existe la preocupación de cómo llevar a cabo los procesos de enseñanza y aprendizaje en alumnos que viven en condiciones tan distintas a la mayoría, hacia una verdadera educación intercultural que no se quede en el discurso y la reflexión teórica, sino asumir desde la práctica una perspectiva pedagógica decolonial, que rompa con las viejas prácticas por nuevas alternativas. Pues en las escuelas de educación indígena, existe una fuerte descontextualización entre la escuela y las comunidades y una de las razones se da por la forma de producir conocimiento, derivada del diseño del currículo institucional que desatiende la precariedad en la que funcionan las escuelas bilinguies destinada a los pueblos originarios. 
Este artículo hace un análisis crítico sobre las prácticas colonizantes que rigen la vida de algunas instituciones educativas de la Región Altos ${ }^{3}$ de Chiapas, y por otra parte estudia a detalle la propuesta innovadora de otras instituciones educativas que tienen como intención proponer una educación culturalmente pertinente para los pueblos originarios y el fomento de una alfabetización a partir del respeto por la lengua y la cultura. Me refiero al Proyecto Milpas Educativas integradas a la Red de Educación Inductiva Intercultural (REDIIN) que ponen en práctica una metodología basada en el Método Inductivo Intercutural. Este proyecto se fundamenta en el acuerdo 169 de la OIT y trastoca lo instituido, pues rompe con las viejas prácticas ya que tiene la idea de preservar los conocimientos propios de los pueblos como medios de instrucción y fuentes de valor que en los programas nacionales han sido ocultados al trabajar temas ajenos al mundo de los alumnos. Conscientes de que no basta el sólo reconocimiento de los derechos de los pueblos indígenas, ni el reconocimiento a las diferencias culturales, las lenguas, las tierras, sino cómo hacer efectivo y congruente este discurso en la vida cotidiana de las escuelas.

\section{La estrategia procedimental del estudio}

La estrategia metodológica de investigación tiene el propósito de analizar sobre el problema pedagógico que consiste en la dificultad para el aprendizaje de la lectoescritura, una problemática fuerte detectada en la experiencia como docente en las escuelas primarias del municipio de Chamula, Chiapas, en las que se deja ver serias deficiencias que presentan los niños en cuanto a la lengua escrita.

En las comunidades indígenas de Chamula, Chiapas, de manera general la lengua de comunicación es la lengua tsotsil (lengua materna indígena) únicamente. De acuerdo a la experiencia en las comunidades, es visible que en los hogares de los niños no hay uso del lenguaje escrito, la presencia de la lectura y escritura fuera de la escuela es muy limitada, en los hogares no existen libros comerciales, en las calles que los niños recorren entre sus casas, la

\footnotetext{
${ }^{3}$ Chiapas se divide en 15 regiones socioeconómicas, la Región de los Altos es una de ellas; en esta región se concentran 17 municipios, entre ellos se localiza la Ciudad de San Cristóbal de las Casas, Capital Cultural de Chiapas, esta ciudad es lugar de concentración de poblaciones indígenas provenientes de comunidades indígenas como: San Juan Chamula, Zinacantán. Huixtán, Oxchuc, Ocosingo, Chenalo, Pantelo, San juan cancuc, Chalchihuitán, Tenejapa, Mitonctic, etc. La mayor parte de la población que habita la región domina una lengua indígena como el tseltal y tsotsil.
} 
escuela o los lugares de desplazamiento por los que transitan, no cuentan con referentes escritos o es muy escaso. La mayoría de las familias y principalmente las madres de familia no tuvieron la oportunidad de asistir a la escuela, y en algunos casos, pasaron a la escuela sin lograr aprender a leer y escribir. Lo que hace evidente que el único lugar para que los niños desarrollen sus potencialidades en lengua escrita, es la escuela y la forma como adquieren el aprendizaje de la lectura es muy relevante.

A partir de un acercamiento metodológico de corte interpretativo en su vertiente cualitativa (Flick, 2015), en este trabajo se describe el trabajo etnográfico (Woods, 1998) obtenido en el trabajo de campo realizado de enero a noviembre de 2019 en dos escuelas primarias de educación indígena pertenecientes a la región de Los Altos, del estado de Chiapas: una de organización completa (laboran 7 docentes), que se caracteriza por su enseñanza de la lectoescritura en base a métodos tradicionales y otra de organización incompleta (laboran 4 docentes) enfocada en la enseñanza a través del trabajo por proyectos, reuniéndose en total: 9 entrevistas a docentes y 1 observación a un grupo de alumnos de primer grado. Además, de los testimonios y pláticas informales con docentes y personas de la comunidad que fueron registrados en un diario de campo.

Ambas escuelas se localizan en la misma región y comparten características sociales y culturales con la escuela donde se detectó el problema pedagógico. La entrada para realizar la investigación a la escuela de enseñanza tradicional se obtuvo por contacto directo con el director de la escuela; en el caso de la escuela alternativa descubro su existencia a través de la investigación documental, dándome a la tarea de localizar a profesores integrados en el proyecto Milpas Educativas en la región para hacerles las entrevistas.

Esta investigación trata de configurar las experiencias de los profesores referente a la enseñanza de la lectura y la escritura, con el fin de analizar los elementos que intervienen facilitando o dificultando el aprendizaje de los alumnos, con miras a justificar un proceso de alfabetización alternativo y pertinente para los pueblos originarios. La intención es que los profesores frente a grupo reflexionen sobre su práctica, y puedan crear otra forma de enseñanza favoreciendo la enseñanza bilingüe. 


\section{La escuela indígena: un espacio para el fomento del control y la sumisión}

La escuela, en términos generales, se considera como un lugar donde se prepara al alumno para la vida, sin embargo, ésta la que representa el mundo globalizado se encuentra inmersa en una política que defiende los intereses del Estado, de la clase empresarial y del sistema capitalista. Lo que deja lejos la posibilidad de ofrecer una educación pertinente para el desarrollo y necesidades de los pueblos originarios.

La escuela actualmente no es solo un espacio donde se desarrollan actividades académicas sino también es un instrumento de integración e incorporación a una cultura occidental. En donde al mismo tiempo se fomenta la sumisión y la obediencia. La escuela, generalmente se encuentra al servicio de la clase dominante, consecuentemente se escolariza para que los individuos que pertenecen a las clases desposeídas aprendan a ser obedientes, para servir al capitalismo. En este contexto, el profesor indígena poco a poco forma al alumno para ser un trabajador que no reclame, sino que ayude a sostener la industrialización convirtiéndolo en un proletario, desde la perspectiva de Foucault (2001).

La educación destinada a los indígenas desde su creación en la llamada Revolución Mexicana ha sido creada con la intención de formarlos, restándoles valor a sus saberes culturales y en particular al fomento de la lengua. Paradójicamente la cultura occidental a través de los programas oficiales que promueve el Estado se le ha dado valor único con cobertura nacional.

\footnotetext{
Una escuela rural de tipo moderno y de espíritu progresivo tiene que ver no solamente con la educación de los niños, sino también con la instrucción de los adultos y también con el mejoramiento de la comunidad, tomada por entero. Su contenido no se concreta ya a la lectura, a la escritura y a las cuentas, sino agrega a esos conocimientos algunas otras cosas más que son necesarias para promover el progreso de la civilización campesina y para que la vida en las áreas rurales sea cada vez más satisfactoria (JORDA, 2003, p. 76).
}

En función de un régimen capitalista, las características de las escuelas que se le asigna a los pueblos originarios colaboran desde un currículum oculto en una "perspectiva teórica que se enfoca hacia el funcionamiento de las escuelas como influencias principales de socialización con el objeto de preparar a los estudiantes para ocupar los diferentes lugares en la fuerza de trabajo jerárquicamente dividida" (Giroux, 1992, p. 84).

En otras palabras, la escuela que se le ha ofrecido a los pueblos originarios ha venido funcionando como un medio de control ideológico de la sociedad capitalista, "Las instituciones 
disciplinarias han secretado una maquinaria de control que ha funcionado como un microscopio de la conducta" (Foucault, 2001, p. 178). Las construcciones de las escuelas están finamente diseñadas con tal propósito, lo cual encadena series de prácticas como el orden de las filas que presentan los muebles permiten que se llevan a cabo la observación, el registro y el encauzamiento de la conducta de los alumnos.

\section{El maestro indígena, no nace para el fomento del control y la sumisión, se hace}

El escenario. - Actualmente en las observaciones realizadas en las escuelas de la Región Altos de Chiapas, en sus aulas es común el tradicional uso de las filas de sillas, de las hileras; que en ocasiones no permite la visibilidad de los niños que se sientan atrás. Esta forma tradicional de ubicar los muebles escolares permite o favorece el control del grupo por el profesor. Como refiere Foucault (2001) en la concepción del panóptico o en los modelos de los observatorios de un campamento militar, todo el poder se ejerce por el único juego de una vigilancia exacta, en el que se fundamenta el poder.

El escritorio del profesor (a) siempre se encuentra al frente de los alumnos, a un lado del pizarrón, el cual da cierto papel de autoridad al profesor, también hay quienes lo utilizan para dejar materiales didácticos. Por otra parte, los docentes, la mayor parte del tiempo están caminando de un lado a otro el cual cede vigilancia y control de la conducta de los alumnos.

La disciplina. -El profesor más admirado por las autoridades es quien puede tener capacidad de control de su grupo de alumnos, en ellos predomina la noción de "docilidad" en el que se realiza ejercicios de control y práctica de dominación según Foucault, tal como lo hiciere un soldado disciplinado "comienza a obedecer mándesele lo que se le ordene; su obediencia es rápida y ciega. La educación o formación de los escolares debe simple mirada que hace el docente, o por el ruido de las campanas" (Foucault, 2001, p. 170). La disciplina y el temor es lo que caracteriza a los grupos de alumnos, por lo tanto, existe un trauma psicológico que se refleja en su pasividad y en su tono de voz. Un ejemplo de ello se pudo advertir cuando se realizaba la investigación en los salones de clase: 
porque un niño notaba que a cada rato se ponía de pie, y al no ver a su madre empieza a llorar, al darse cuenta la madre se acerca y entra al salón. El niño sentía miedo, lloraba, no interactuaba con sus compañeros y no trabajaba. Al percatarme de ello, no hice nada, dejé que se calmara y al transcurrir un tiempo me acerqué y le pregunté si había avanzado en sus lecciones, no contestó, le pedí su cuaderno, y entonces puso una cara de espanto, cuando me acerqué, y le dije que estaba bien lo que llevaba hecho, el niño no se lo creía. Me preguntó nuevamente (me lek) ¿está bien?, le respondí de nuevo que sí, se animó y se levantó en otras ocasiones para preguntarme si era así el trabajo, le dije que sí. Yo me sorprendí, que el niño avanzaba rápidamente la tarea asignada, él tomó confianza y continuó trabajando de manera significativa en las siguientes sesiones de clase. (Diario de Campo)

Sin embargo, pude concluir que el hecho de que los niños permanezcan callados no significa que éstos sean disciplinados escolarmente. "la disciplina "fabrica" individuos; es la técnica especifica de un poder que se da a los individuos a la vez como objetos y como instrumentos de su ejercicio" (Foucault, 2001, p. 175).

Castigos. - La palabra castigo, debe comprenderse como "todo lo que es capaz de hacer sentir mal a los niños por la falta que han cometido, son todas aquellas acciones que son capaz de humillarlos, de causarles confusión: como cierta frialdad, o cierta indiferencia, de los docentes" (Foucault, 2001, p. 183). En las escuelas indígenas es común dar un castigo cuando no cumplen un trabajo, como dejar sin recreo, evidenciarlos frente a sus compañeros, pedirle que repitan muchas veces en el cuaderno la escritura porque no aprenden, aislarlos por no llegar limpios. "Una serie de procedimientos sutiles, que van desde el castigo físico leve a privaciones menores y a pequeñas humillaciones" (Foucault, 2001, p. 183). Consecuentemente la intimidación a los alumnos puede darse no sólo a través de lo que se dice con palabras, sino también a través de los gestos, las miradas, los desplazamientos y en general de las acciones antes descritas.

Las instituciones educativas y la gestión. - Así como el profesor tiene el rol de vigilancia, control y disciplina dentro de las aulas con los alumnos, también existe un sistema de organización con la reproducción de los mismos roles para controlar al profesor. En ellos existe la creencia que son vigilados y controlados como lo plantea Foucault (2001) a través del simbolismo llamado panóptico, y que tiene fuerte efecto en los docentes ya que ellos consideran que su principal tarea no es formar a los niños sino más bien hacer que estos reproduzcan los contenidos que marcan los libros de texto. Según Foucault es: "inducir en el detenido un estado consciente y permanente de visibilidad que garantiza el funcionamiento del poder" (2001, p. 204). Para los docentes indígenas la Secretaria de Educación Pública del país, tiene el poder de crear y de sostener una relación de poder independiente de aquel que lo ejerce. Por otra parte en 
los hechos los profesores están sometido a inspecciones frecuentes y no sólo de ellos sino también de parte de los padres de familia. El rol del maestro es condicionado, las acciones que realiza las hace pensando en que está siendo vigilado por sus superiores, es obediente y sumiso ante sus superiores, se ve imposibilitado de hacer algo diferente, y con frecuencia cae en la rutina con la que él fue formado cuando era niño. De esta manera el temor real e imaginado, es creado desde una estructura administrativa de corte burocrático. "El panoptismo es el principio general de una nueva "anatomía política" cuyo objeto y fin no son la relación de soberanía sino las nociones de disciplina" (Foucault, 2001, p. 212).

\section{Proyectos y experiencias alternativas para los pueblos de Chiapas}

En el proceso de investigación, me he encontré con un equipo de profesores y profesoras de educación indígena en el estado de Chiapas que trabajan en escuelas bilingües instituidas, pero organizados en el proyecto Milpas Educativas integradas en la REDIIN $^{4}$ hacen un esfuerzo por llevar una educación distinta basado en el Método Inductivo Intercultural acuñado por Jorge Gasché (2008a, 2008b), en el que plantea un proceso pedagógico significativo articulando la pedagogía con una posición política, didáctica, jurídica y pertinente. Se parte del trabajo que realizan los niños y niñas en sus comunidades, como medios de instrucción y fuentes de valor. Este proyecto se fundamenta en el acuerdo 169 de la OIT. Tiene la idea de preservar los conocimientos propios de los pueblos, que en los programas nacionales han sido ocultados, al trabajar temas ajenos al mundo de los alumnos. El método inductivo rompe con las viejas prácticas, las actividades se realizan fuera del salón de clases. Se parte de los conocimientos demostrados por los alumnos que el profesor amplía. Para esto, el profesor investiga tanto los saberes comunitarios como los saberes científicos.

En entrevista realizada a una profesora, vierte su testimonio sobre la importancia que tiene ir directamente al lugar donde se realiza la actividad que como menciona Bertely (2014) "los huertos, las milpas, los ríos se convierten en oportunidades alfabetizadoras en términos

\footnotetext{
${ }^{4}$ La REDIIN es un colectivo plural e independiente integrado por más de quinientos maestros en todo el país, educadores comunitarios — entre los cuales se encuentran los educadores de la UNEM/EI-, investigadores, académicos e integrantes de la sociedad civil, indígenas y no indígenas, que comparten la experiencia de haberse formado en el MII. Fue creada en 2009 por María Bertely (CIESAS) con la finalidad de intercambiar experiencias sobre el MII y construir un espacio de análisi y reflexión para consolidar y desarrollar este enfoque político, epistémico y pedagógico.
}

R. Articul.const.saber, 2020, v.5: e65693 
ontológicos, epistémicos, lingüísticos y para el buen vivir" (p. 27). Para trabajar el tema de ubicación espacial, la profesora y sus alumnos salieron a dar un recorrido por los caminos de la comunidad. La profesora comenta que es una actividad muy rica, los alumnos conocieron su comunidad, los lugares importantes, las casas de sus compañeros, ubicaron las comunidades vecinas. Durante el recorrido se detenían para hablar sobre algunas plantas, decir su nombre, para qué sirven, recolectaron palitos, hojas, insectos secos. También menciona que escribían con palitos sobre la tierra el nombre de la actividad, (croquis). Más adelante encontraron una planta que pinta, escribieron el nombre en una piedra grande, los niños disfrutan de la actividad al tiempo que aprenden. Al llegar al salón pusieron en la mesa los materiales que fueron recolectando. Esta larga caminata, permitió que los alumnos elaboraran un croquis -comenta la maestra- un croquis vivo. Trabajaron solos y muy animados, hicieron una representación real de la comunidad, buscaron en los libros que ya no usan los adultos en la vida cotidiana y obtuvieron figuras para completar, por ejemplo, para demostrar la escuela buscaron el dibujo de un edificio y le colocaron la bandera, dibujaron el río, colocaron piedritas, para representar el camino fueron uniendo palitos. Y lo más importante, el tiempo no les alcanzó, el trabajo quedó inconcluso, al siguiente día llegaron todos muy animados, sabían que tenían que terminar su croquis, de manera natural continuaron su trabajo. Bertely (2014), asegura que estas formas de aprendizajes resultan más importantes que la capacidad de leer o escribir un recado o de aprender a escribir repitiendo palabras que para los alumnos carecen de significado.

\section{Milpas Educativas}

“El fundamento político, epistémico y pedagógico del proyecto es el Método Inductivo Intercultural (MII)" (Sartorello, 2017 p. 5), además agrega que milpas educativas “es un proyecto más grande que pura actividad pedagógica, se trata también de promover la defensa de la vida, una ética del Buen Vivir, la integración armónica sociedad-naturaleza y el trabajo colectivo frente al individualismo capitalista" (Sartorello, 2017, p. 12). Ya que para lograr aprendizajes significativos es necesario iniciar con los aprendizajes previos que los niños traen de su entorno. Podría decirse que es un modelo holístico "el cual pretende acercar a los niños a la lectura a través de textos con mayor significación" (Alliende y Condemarín, 2002, citado en Hudson, et al., 2013, p. 103). 


\section{Aprendizaje en y para la comunidad: una educación pertinente para las escuelas indígenas}

Para integrar los conocimientos indígenas del currículo escolar, Jorge Gasché (2008a y 2008b) asegura que es necesario incorporar la escuela a la vida real de la comunidad, a partir de la sistematización del currículum educativo implícito de su cultura, al desarrollar actividades escolares fuera del aula y al hacer uso pedagógico de los eventos sociales, productivos y rituales que se llevan a cabo en la comunidad. Para saber qué actividades debe trabajar el profesor es necesario que éste investigue todas las actividades que en la comunidad realiza durante todo el año, de acuerdo con el modelo sintáctico, las culturas se manifiestan por medio de actividades productivo-comunicativas es decir que las actividades sociales, productivas y rituales de las sociedades indígenas se dan tomando en cuenta la naturaleza y el territorio. La profunda integridad entre sociedad y naturaleza tienen importantes implicaciones ontológicas que, intervienen en el proceso de construcción del conocimiento escolar, las actividades integran las asignaturas de la naturaleza y sociedad de manera transversal, así como la lectoescritura. No se trabajan por separado, el currículum del Método inductivo Intercultural imita la visión sintáctica, entera, global.

Dado que el universo de las actividades comunitarias representa "el currículum implícito indígena, así como la fuente y el medio de donde adquieren sustancia los contenidos y procesos escolares" (Gutierrez, et al., 2012, p. 11) El calendario Socio-natural es el instrumento principal de la metodología, comienza listando las principales actividades tradicionales de la comunidad, ejercicio que se apoya en el conocimiento de los más ancianos. "El calendario socionatural es un instrumento esencial para escoger de entre las multiples actividades, aquellas que por medio del MII se pueden utilizar como fuentes para contenidos escolares indígenas" (Gutiérrez, et al., 2012, p. 11). Todas las actividades que se realizan motivan al alumno su participación y su interés por aprender, incluidas la lectura y escritura de las palabras que se generan durante las actividades, logrando los aprendizajes significativos de los cuales hablan Ausubel y Vigotsky en la construcción del conocimiento. 


\section{Claves para el fomento de una alfabetización del municipio de San Juan Chamula}

En los antecedentes históricos y políticos que ha atravesado la educación para los pueblos indígenas, en México, referente al desarrollo de la alfabetización y concretamente el fomento de una educación bilingüe, consecuentemente la castellanización y la lectoescritura, que se fomentan a favor de los niños y niñas indígenas, siguen dejando mucho que desear.

Los pueblos indígenas desde la conquista española han sufrido marginación y una discriminación racial, ya que los colonizadores les prohibían hablar en su lengua materna, y por esa razón algunos de estos pueblos acostumbraban a refugiarse en lugares lejanos a las ciudades. Después durante el gobierno de Porfirio Díaz, a fines del siglo XIX y principios del XX se creó el proyecto de la llamada "escuela peor es nada" se consideraba que era "Urgente y necesario educar al indígena para civilizarlos y alcanzar el grado de ciudadanos” (Martínez, 2015 p. 104). Después en la llamada Revolución Mexicana, no cambió la suerte de estos pueblos que eran catalogados como cultura atrasada, por no saber hablar español.

"La política que se impone es la de mexicanizar a los indios a través de la lengua nacional, política reflejada en la Ley de Instrucción Rudimentaria de 1911, implementada por Gregorio Torres Quintero y Jorge Vera” (Martínez, 2015 p. 104). Esta Ley apostó como primer paso para la modernización de los indígenas la enseñanza del español. Como se puede apreciar, no se pretende educar para beneficiar a los pueblos indígenas sino para integrarlos a la cultura nacional, dando paso a la marginación y la discriminación racial, y de esta manera se fueron creando programas con un solo objetivo la neocolonización del indígena y favorecer la enseñanza del español, en contraposición de silenciar la lengua de los pueblos originarios.

Actualmente en la práctica, la educación intercultural bilingüe instituída se ha dado como una necesidad de dar clases en la lengua materna del alumno, para lograr la comprensión de los contenidos de enseñanza de los mismos planes y programas nacionales, sin embargo, no se cuenta con un programa con fines específicos, y poco se ha alfabetizado en la lengua indígena. "El maestro emplea la lengua vernácula o indígena por necesidad o solamente como un puente para la enseñanza en lengua oficial de la escuela. Una clara evidencia de este hecho es que los niños, son evaluados exclusivamente en castellano” (Zúñiga, 1989 p. 11). Esto indica que las prácticas educativas de los llamados profesores bilingües son en los hechos prácticas 
colonizadoras. Por lo tanto, es necesario hacer una transformación de las prácticas educativas de los pueblos originarios sin esperar que, desde arriba, como tarea del Estado, se den los cambios esperados, una educación pertinente y efectiva desde los contextos propios de los alumnos.

Pensar en una cultura nacional para una sociedad que se reconoce y se quiere plural,
implica abandonar la idea del fomento de una cultura uniforme. Lo común no serán los
contenidos específicos en la cultura de los diversos pueblos que componen México, lo
común será, en primer término, la voluntad de respeto y convivencia dentro de la
diversidad. La cultura será ese ámbito mayor de coexistencia fructífera en el que cada
pueblo podrá desarrollarse según su propio proyecto (BONFIL, 1994 p. 236).

Las prácticas a las que recurren los docentes tienen mucho que ver en el sistema que hemos sido formados. Según las investigaciones hasta hoy realizadas en Chiapas, ningún profesor entrevistado cursó estudios de licenciatura o normal previo a la labor docente. Los estudios de licenciatura en la Universidad Pedagogica Nacional (UPN) fueron realizados como parte de la necesidad de asegurar su estabilidad laboral. Por otro lado, el raquítico dominio del español que poseen los profesores indígenas influye en la enseñanza, pues existe quien tiene más dominio de su propia lengua y no del español. Lo cual no significa que sepan leer y escribir en su idioma materno, es decir, ninguno ha recibido instrucción de lectoescritura en lengua materna, para ingresar al servicio docente. Generalmente se presenta un examen que consiste en escribir palabras aisladas, contestar preguntas o hacer una narración de situaciones de manera oral. Esto lo confirman las investigaciones en escuelas bilingües de Chiapas realizadas por profesores de la Dirección General de Investigación Educativa:

Tomando en cuenta que la mayor parte de los maestros bilingües en servicio no son estudiantes universitarios, y que muchos tienen niveles de lecto-escritura en español, que son apenas funcionales, podemos darnos cuenta de cuán deficientes son las habilidades de lecto-escritura en la lengua indígena entre los maestros bilingües. (FREEDSON y PÉREZ, 1999 p. 58).

De esta situación reside que los profesores con enfoque tradicional no se animen a alfabetizar en lengua indígena y le den preferencia al español, poniendo a los alumnos en un aprendizaje muy complejo. Según investigadores de la Revista Mexicana de investigación Educativa, uno de los principios lingüísticos de la educación intercultural es que:

Mientras mejor se enseña la lecto-escritura en la L1 (lengua materna), mejor se podrán transferir estas habilidades a la lengua nacional, una vez que los alumnos hayan alcanzado el nivel umbral necesario en ella; todo lo que se aprende en una lengua puede usarse en la otra (HAMEL et al., 2004, p. 88).

R. Articul.const.saber, 2020, v.5: e65693 
La inseguridad de los docentes y el desconocimiento de estrategias y materiales de apoyo es algo que han influido para iniciar con la enseñanza en lengua indígena, lo que estos investigadores aseguran es que: "Su segunda lengua, el español, es casi inexistente en ese momento. Ahora entendemos por qué la "castellanización" fracasa casi inevitablemente: el programa intenta alfabetizar, es decir, construir una proficiencia cognitivo-académica, a partir de una lengua que no está desarrollada" (Hamel, et al., 2004, p. 91). La enseñanza de la lectoescritura en español ha traído como consecuencia que los niños no aprendan a leer durante el primer ciclo, ya que las palabras en español no son significativas para la estructura cognitiva de los niños.

Los docentes de enseñanza tradicional tienden a percibir a sus alumnos como si el desconocimiento del español fuese un padecimiento, en lugar de verlos como poseedores de una lengua e identidad cultural propia, con valor intrínseco. "Esta visión ubica el "problema" educativo en el niño y la comunidad, y no cuestiona el papel de la escuela ni de las estructuras sociopolíticas mayores en que la escuela está inmersa” (Freedson y Pérez, 1999 p.97).

En las escuelas indígenas de Chiapas, se está pasando por alto algo relevante como lo es la lengua y cultura de las comunidades, al poner énfasis en la enseñanza en segunda lengua. Al respecto (Cummins, 2002) asegura según sus investigaciones que los resultados pueden ser exitosos "De manera que los estudiantes que hayan desarrollado la lectoescritura en su L1 (lengua materna) tenderán a hacer más mayores progresos en el aprendizaje de la lectoescritura en L2 (español)" (Cummins, 2002, p. 198).

Por lo tanto, es necesaria una trasformación del quehacer consciente de los profesores, desde un interés colectivo tal como lo sugieren las comunidades de práctica. Es decir, se requiere que el problema del bilingüismo se vea como una tarea no solo de un maestro, sino de todos los docentes que integran una comunidad de corte institucional.

El proceso de aprendizaje de la lectura y escritura es un tema relevante en la vida de todos, la forma cómo la adquirimos queda guardada en la memoria para siempre; por eso, es necesario que este proceso de enseñanza se de a partir de la lengua materna. Lo ideal es que la lengua indígena sea utilizada "a todos los niveles: en tanto lengua de comunicación, lengua de instrucción, pero también lengua de reflexión; lo ideal es que esa lengua tenga un lugar importante a lo largo de la escuela primaria" (Ferreiro, 1997b, p. 198). Por ello es necesario crear un sistema de escritura en lengua indígena, así se podrá alfabetizar a los alumnos en su lengua 
materna. "Hoy en día calificamos de correcta pero ingenua: si se trata de hacer corresponder sonidos elementales (letras), ésta correspondencia debe verse facilitada cuando se trata de los fonemas de la propia lengua" (Ferreiro, 1997a, p. 297). Al respecto, considero que la enseñanza con palabras en español no es del todo incorrecta, siempre y cuando sean palabras que el alumno reconoce su significado, pues más que nada se trata de que el alumno descubra y tome conciencia de la descomposición fonética de la lengua oral.

El desconocimiento de estrategias de enseñanza en lengua materna por parte del profesor, así como al empleo constante del español para la enseñanza, dificultan el aprendizaje de la lectoescritura ya que los niños del municipio de Chamula, Chiapas usan el cien por ciento la lengua indígena en la vida cotidiana. No existe una institución que ofrezca cursos ni talleres específicos sobre la enseñanza de la lectoescritura en comunidades con niños monolingües en lengua indígena. Se hace necesario que los profesores opten por nuevas estrategias de enseñanza para tal fin. Que sobre todo se tome en cuenta el contexto de los alumnos y considere lo que señala Erickson (1984), “estar alfabetizado "es mucho más que la operación mecánica de descifrar códigos ya que implica una práctica social de comunicación" (Citado en Aceves y Mejía, 2015, p. 3).

Es necesario replantear nuestro papel docente ante las necesidades de los niños indígenas , reivindicar la cultura a través de la escuela, involucrar la escuela a la comunidad y romper con los esquemas tradicionales de enseñanza. Ante la imposición de los planes de estudios, construir desde abajo una propuesta con estrategias didácticas que respeten y tomen en cuenta el contexto de los alumnos.

La educación bilingüe está en posibilidades de fomentar el bilingüismo en los estudiantes, que permita dar uso funcional de la lengua materna y el español en forma escrita, no se trata de desplazar la lengua materna sino de la posibilidad del reforzamiento de las lenguas a través de la lectoescritura de la lengua materna. De esta manera avanzar hacia el desarrollo de las lenguas indígenas, no permitir que la lengua dominante sea la única que tenga valor ya que, a pesar de ser una lengua ágrafa también puede llegar a ser una lengua de prestigio, con la colaboración de maestros, alumnos y autoridades educativas.

Existe una gran diferencia cuando se quiere aprender una segunda lengua y cuando se la imponen, ser bilingüe permite la comunicación con dos culturas, no es lo mismo cuando se deja de hablar una lengua indígena por vergüenza o discriminación, cuando se cree que la lengua 
indígena no vale. En una comunidad indígena hablar dos lengua hace a la persona valiosa, tiene la posibilidad de comunicarse con su comunidad y con personas externas.

Las lenguas indígenas han sido desacreditadas por la lengua dominante de la sociedad, el propio profesor y los padres de familia. Hemos caído en el estigma de la sociedad dominante de que las lenguas indígenas son signos de atraso y marginación. Se hace necesario una educación más justa que respete y tome en cuenta la lengua materna de los alumnos, que no sea simplemente utilizada como un medio de instrucción de los contenidos de enseñanza, sino que el alumno se vea beneficiado en aprender y producir sus pensamientos en textos escritos. Son derechos que se encuentran plasmados desde el artículo 26 al 31 del convenio 169 de la OIT y en específico en el punto dos y tres del artículo 28, como menciona Gasché:

no es suficiente saber leer y escribir en las lenguas indígenas; éstas, además, deben desarrollarse, modernizarse para que su uso práctico no sea limitado al ámbito tradicional de la vida, mas sea posible en todos los contextos de la modernidad (GASCHÉ, 2008b, p.370).

Las maestras que trabajan en educación alternativa llevan a cabo la alfabetización en la lengua que dominan los niños, ya que para ellos resulta significativo. La diferencia es, que en los trabajos por proyectos los profesores trabajan a partir de temas y contenidos que surgen de las propias comunidades indígenas, es decir, basados en el constructivismo que menciona Olivé (1999): el conocimiento no sólo se construye en el pensar sino en el hacer, hecho que se consuma en las prácticas alternativas, como lo describe la profesora Bety:

-También trabajamos lectura y escritura, cómo se escribe tamalito por ejemplo ellos (los niños) decían pitubil, escribimos la palabra en una tarjeta, escribíamos el abecedario como en un tendedero con papel opalina con letras del abecedario en lengua indígena, las pegamos en una pared y en la otra parte del salón tendimos también el abecedario en español. Ya que hay palabras que no encontramos traducción en tsotsil, hicimos un inventario de las cosas que usamos en el proceso (la elaboración del atol $)^{5}$, hicimos una relación de todo lo que usamos: ixim (maíz), boch (jícara), lech (cuchara), mexa (mesa), k'ok' (fuego), si' (leña), yoket o (parrilla), B'in ach'il (olla), mulino (molino), vasu (vaso), etc., todo esto lo fueron diciendo los niños y habían palabras que no teníamos cómo decirlo en tsotsil, como la cubeta que algunas le dicen val te en el municipio, pero los niños le dicen cubeta y para no conflictuarnos escribimos como ellos lo conocen, igual que la parrilla ya muchos la conocen con ese nombre, porque es importante respetar sus conocimientos previos, y si los niños lo conocen como cubeta pues lo escribimos en español.

\footnotetext{
${ }^{5}$ Elaboración del Atol agrío como actividad por proyecto: es una bebida caliente, típica y tradicional que prevalece en la región elaborada a base de maíz fermentado, regularmente se prepara con maíz negro para obtener un color rosa, su preparación lleva en promedio cuatro días, ya que debe remojarse el maíz durante días y noches para que tome el sabor agrío.
} 
Por tratarse de alfabetización inicial, se parte de palabras y pequeñas frases, pero dependiendo del avance de los alumnos, las frases y textos van aumentando su dimensión. En voz de las profesoras advierten que es una tarea complicada pero no imposible, romper con las viejas prácticas dentro de las aulas, es empezar a pensar en no complacer al patrón, sino en hacer un trabajo que tenga significados a favor de la niñez como argumenta Rockwell:

El trabajo del maestro no consiste en "moldear las mentes y los cuerpos" de los niños de determinada manera en el plazo de un año sino, más bien, en "convocarlos a trabajar" sobre actividades que les propone, con la esperanza de que se conviertan en contextos que faciliten el aprendizaje, en "andamiajes", como algunos les llaman, que conduzcan hacia nuevos conocimientos o habilidades (ROCKWELL, 2018, p. 503-504).

De esta perspectiva nace la idea de aspirar a la biliteracidad que según Hornberger (1990), la biliteracidad se refiere a toda instancia en la cual la comunicación se desarrolla en dos o más lenguas alrededor de un texto escrito. Esta habilidad debería desarrollar las escuelas bilingües pero no se hace, se debe reconocer que los propósitos de la educación bilingüe se han quedado estáticos, probablemente porque los profesores desconocen cómo hacer práctico su aplicación. En pocas palabras, existen insuficientes explicaciones, mientras los estudiantes permanecen en el límite de un silencio total que no será interrumpido más que por las señales o gestos.

El uso de la lengua es fundamental en todas las sociedades ya que es el medio por el que podemos expresar sentimientos, emociones, ideas, saberes, etc., La lengua tiene la gran capacidad de influir en la forma en que los seres humanos y los pueblos se relacionan y a través de ella se establezcan formas de intercambio como el comercio, el trabajo, y la comunicación misma. Al respecto Ruíz (1997) dice:

La lengua tiene una existencia propia -existe aún cuando se la suprime; cuando la voz es suprimida, no se la escucha- no existe. Negar a un pueblo su lengua, como en las situaciones coloniales..., es, sin duda alguna, negarles su voz; pero permitirles "su" lengua...no es necesariamente lo mismo que permitirles su voz (citado en Hornberger, 2005, p. 69).

En esta posición Baker (1997), señala que el fomento de la enseñanza bilingüe no debiera estar conectada con el problema de la orientación lingüística. Sino más bien sugiere que sería conveniente desarrollar el bilingüismo y la biliteracidad dentro de una situación de enseñanza bilingüe, lo que considera pedagogicamente viable y puede llevar a: 
- Un rendimiento más alto de los niños de lengua minoritaria en todas las asignaturas escolares;

- El mantenimiento de la lengua y la cultura materna;

- El aumento de la autoestima, autoidentidad y una actitud más positiva respecto de la escolaridad.

La propuesta de Baker consiste en emplear un tiempo exclusivo para la enseñanza formal de una segunda lengua, que no contemplan los planes y programas pues lo que se ha hecho hasta hoy es el empleo oral, mientras si hay una enseñanza formal del español, disponemos a los niños a aprender conscientemente y podrán utilizarlo cuando ellos lo consideren necesario. Caso que se experimenta en los alumnos durante el proceso de alfabetización, como no hay una enseñanza formal del español, a los alumnos solamente se les crea confusión, lo que dificulta el aprendizaje de la lectoescritura y el aprendizaje oral de la segunda lengua.

El modelo de mantenimiento que Baker (1997) propone, lograr un bilingüismo aditivo, ya que no se desplaza a la lengua materna del alumno, sino que agrega el uso del español. De acuerdo a los datos obtenidos en el trabajo de campo, se hace necesaria la enseñanza de la segunda lengua la cual tiene uso fuera de las comunidades, ya que la población indígena de Chamula, Chiapas (hombres y niños) se caracteriza por salir a las ciudades para el comercio de artículos artesanales, el desarrollo de un bilingüismo aditivo, tendría un impacto positivo en función del trabajo, que además amplía el desarrollo de cada persona, aumenta su autoestima, crea su autoidentidad, y toma una actitud más positiva ante la sociedad mayoritaria. Según Baker un "niño que puede entender en cualquiera de las dos lenguas el desarrollo del plan de estudios y opera en el aula en cualquiera de las dos sería un ejemplo de bilingüe equilibrado"(Baker, 1997, p. 35). Aunque raramente una persona es igualmente competente pues cada persona usa las lenguas para diferentes propósitos y funciones.

\section{Conclusiones}

Por lo tanto, una de las funciones de las escuelas indígenas de Chamula Chiapas es lograr que los alumnos aprendan a expresarse, comprender y desarrollar la lectura y escritura en su lengua materna para poder desarrollarse en la segunda lengua. Aunque teóricamente esos son los propósitos de la educación bilingüe, los gobiernos federales prefieren dejar los acuerdos y convenios en el olvido. A esto se refieren Hornberger cuando dicen: "En las prácticas y políticas 
educativas, hay una tendencia a favorecer o privilegiar un extremo de cada continuum, de manera que conlleva más poder que el otro extremo" (Hornberger, 2005, p. 60), pues no hay un balance entre la enseñanza de la escritura de la primera y segunda lengua, se le ha dado mayor atención en un extremo (el español) como parte de una política del poder ejercida en las prácticas educativas, el cual requiere una atención y reconocimiento especial a las voces y prácticas que tradicionalmente ocupan márgenes menos reconocidas.

Aunque no haya apoyo del Estado en los hechos, es necesario empezar a desarrollar actividades que promuevan no solo el mantenimiento de las lenguas indígenas sino revitalizar y acrecentar su uso a través de la lengua escrita, argumentada por Hornberger que asegura: "Se pueden abrir espacios desde abajo aun cuando no haya una política favorable" (Hornberger, 2009, p. 104). Este es el caso del proyecto Milpas Educativas que aquí se documenta, a partir del cual el Método Inductivo Intercultural retoma en todos los momentos del aprendizaje, el contexto, la lengua, la cultura, la vida cotidiana y las actividades tradicionales del calendario socionatural de la comunidad, en donde los niños recrean sus saberes previos y los amplían en el trabajo educativo que realizan junto con los docentes, así, el disfrute, el deseo de aprender y las palabras orales y escritas en su propia lengua, toman un significado pedagógico más amplio en armonía con la naturaleza y el buen vivir que son característicos de los valores y la cosmovisión de San Juan Chamula.

\section{Referencias}

ACEVES, I. \& MEJÍA, R. El desarrollo de la literacidad en los niños. En MEJÍA-ARAUZ, R. (coord.) Desarrollo psicocultural de niños mexicanos. Guadalajara, Jalisco: ITESO, 2015. Recuperado de: https://rei.iteso.mx/bitstream/handle/11117/3026/3\%20\%201\%20Aceves\%2C\%20R\%20Mejia.pdf?sequence=2

BAKER, C. Fundamentos de educación bilingüe y bilingüismo. Madrid: Cátedra, 1997.

BERTELY, M. Educación intercultural, alfabetización territorial y derechos indígenas en y desde Chiapas, México. Artículos y Ensayos de Sociología Rural, Año 9, Núm. 17, enero-junio 2014, Chapingo, Edo. de México: Universidad Autónoma de Chapingo, 2014.

BONFIL, G. México profundo. Una civilización negada. México: Grijalbo, 1994.

CUMMINS, J. Lenguaje, poder y pedagogía. Niños y niñas entre dos fuegos. Madrid: Morata, 2002. 
FERREIRO, E. "El bilingüismo: una visión positiva" prejuicios contra el bilingüismo. En GARCÍA, B. (coord.). Políticas lingüísticas en México. México: Centro de Investigaciones Interdisciplinarias en Ciencias y Humanidades-UNAM. PP. 293-302, 1997a.

Alfabetización, teoría y práctica. México: Siglo XXI, 1997 b.

FLICK, U. El diseño de Investigación Cualitativa. Madrid: Ediciones Morata, 2015.

FOUCAULT, M.; Garzón A. (trad.). Vigillar y castigar: nacimiento de la prisión. (31 ${ }^{\mathrm{a}}$ ed.). México D.F.: Siglo XXI, 2001.

FREEDSON, M. Y PÉREZ, E. (1999). La educación bilingüe-bicultural en los Altos de Chiapas. Una evaluación. Ciudad de México: SEP, Centro de estudios superiores de México y Centroamérica.

GASCHÉ, J. Niños, maestros, comuneros y escritos antropológicos como fuentes de contenidos indígenas escolares y la actividad como punto de partida de los procesos pedagógicos interculturales: un modelo sintáctico de cultura. En Bertely, M., Gasché, J. y Podestá, R. (coords.). Educando en la diversidad: Investigaciones y experiencias educativas interculturales y bilingües. pp. 279-365. Quito, Ecuador: Abya-Yala, 2008a.

- La motivación política de la educación intercultural indígena y sus exigencias pedagógicas. ¿Hasta dónde abarca la interculturalidad?. En BERTELY, M., GASCHÉ, J. Y PODESTÁ, R. (coords.). Educando en la diversidad: Investigaciones y experiencias educativas interculturales y bilingües. pp. 367-397. Quito, Ecuador: Abya-Yala, 2008b.

GIROUX, H. A. Teoría y Resistencia en Educación. Una pedagogía para la oposición. México, D.F.: Siglo XXI, 1992.

GUTIÉRREZ, R., SARTORELlO, S., MARTÍNEZ, J., PÉREZ, E., HERNÁNDEZ, A. Y BALLESTEROS, M. Guía para sembrar el método inductivo intercultural en comunidades y escuelas. Pueblos tsotsil, tseltal y chuj. Ciudad de México: CIESAS, 2012.

HAMEL, E. et al. ¿Qué hacemos con la castilla?. La enseñanza del español como segunda lengua en un currículo intercultural bilingüe de educación indígena. Revista mexicana de investigación educativa. 9 (20), 83-107, Consejo Mexicano de investigación educativa. A-C. México D.F, 2004.

HORNBERGER, N. H. Voz y Biliteracidad en la Revitalización de Lenguas Indígenas: Prácticas Contenciosas en Contextos Quechua, Guaraní, y Maori. Polifonia: Revista de Letras, 10 pp. 5373, 2005. Recuperado de: https://repository.upenn.edu/cgi/viewcontent.cgi?article=1271\&context=gse_pubs

H. La Educación Multilingüe, Política y Práctica: Diez Certezas. Revista Guatemalteca de Educación, 1 (1), pp. 95-138, 2009. Recuperado de: https://repository.upenn.edu/cgi/viewcontent.cgi? article $=1320 \&$ context=gse_pubs

R. Articul.const.saber, 2020, v.5: e65693 
HUDSON, C. et al. Comparación de la efectividad de dos estrategias metodológicas de enseñanza en el desarrollo de la comprensión lectora en el primer año escolar. Perfiles Educativos. XXXV (140), 100-118. IISUE-UNAM, 2013. Recuperado de: https://www.redalyc.org/pdf/132/13226156007.pdf

JORDA, J. Ser maestro bilingüe en Suljaa’. Lengua e identidad. México, D.F.:UPN, 2003.

MARTÍNEZ, E. La educación intercultural y bilingüe (EIB) en México. ¿El camino hacia la construcción de una ciudadanía democrática?. Relaciones. XXXVI (141), 103-131, 2015. Recuperado de: http://www.scielo.org.mx/pdf/rz/v36n141/0185-3929-rz-36-141-00103.pdf

OLIVÉ, L. Multiculturalismo y pluralismo. México: Paidós/UNAM, Facultad de filosofía y Letras, 1999.

Regiones socioeconómicas. Recuperado de. www.ceieg.chiapas.gob.m

ROCKWELL, E. El trabajo docente hoy: Nuevas huellas, bardas y veredas. En ROCKWELL, E; ARATA, N.; ESCALANTE, J.C. Y PADAWER, A. (comps.). Vivir entre escuelas: Relatos y presencias. Antología esencial. pp. 489-520. Buenos Aires: CLACSO-Libro digital, Descarga y online: ISBN 978-987-722-311-8, 2018.

SARTORELLO, S. (Coord.). De la escuela a las milpas educativas: tensiones y negociaciones intra e interculturales en la gestación y desarrollo de un proyecto educativo para el buen vivir. Congreso nacional de investigación educativa. COMIE. San Luís Potosí, 2017. Recuperado de: http://www.comie.org.mx/congreso/memoriaelectronica/v14/doc/simposios/0423.pdf.

WOODS. P. Investigar el arte de la enseñanza: el uso de la etnografía en la educación. Barcelona, España: Paidós, 1998.

ZÚÑIGA, M. Materiales de apoyo para la formación docente en educación bilingüe Intercultural. Educación Bilingüe. Santiago, Chile: Unesco/OREALC, 1989.

Submetido em 17 de setembro de 2020.

Aceito em 22 de outubro de 2020.

Publicado em 24 de novembro de 2020. 